\title{
The Rio Tinto Mars Analogue site: An extremophilic Raman spectroscopic study
}

\author{
Howell G.M. Edwards ${ }^{a, *}$, Peter Vandenabeele ${ }^{b, *, 1}$, Susana E. Jorge-Villar ${ }^{c, 2}$, \\ Elizabeth A. Carter ${ }^{\mathrm{d}, 3}$, Fernando Rull Perez ${ }^{\mathrm{e}, 4}$, Michael D. Hargreaves ${ }^{\text {a }}$ \\ ${ }^{a}$ Centre for Astrobiology and Extremophile Research, School of Life Sciences, University of Bradford, Bradford BD7 1DP, UK \\ ${ }^{\mathrm{b}}$ Ghent University, Department of Analytical Chemistry, Proeftuinstraat 86, B-9000 Ghent, Belgium \\ ${ }^{c}$ Area Geodinamica Interna, Facultad de Humanidades y Educacion, Universidad de Burgos, Calle Villadiego s/n, 09001 Burgos, Spain \\ ${ }^{\mathrm{d}}$ Vibrational Spectroscopy Facility, School of Chemistry, The University of, Sydney, NSW 2006, Australia

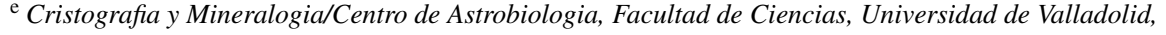 \\ Prado de la Magdalena s/n, 47011 Valladolid, Spain
}

Received 1 December 2006; received in revised form 13 December 2006; accepted 14 December 2006

\begin{abstract}
The Rio Tinto site is recognised as a terrestrial Mars analogue because of the presence of jarosite and related sulfates which have recently been identified by the NASA Mars Exploration Rover "Opportunity" in the El Capitan region of Meridiani Planum on Mars. It has long been known that acidophilic microbial action is responsible for the deep blood-red colour of the water in Rio Tinto, where the pH varies from about 1.5 to 3.0 and the water is rich in iron and sulfur. Following recent Raman spectroscopic characterisation of the mineral phases of the Rio Tinto system, we report here a study of the biological components found in several specimens of deposited minerals and near the waterside that were collected during a GeoRaman VI Conference organized field trip in 2006. Key biosignatures were found for carotenoids, scytonemin and mycosporine-like amino acids, which are indicative of the biological colonisation of exposed mineral substrates; information from this study will be useful for targeting Martian sites using a miniaturized Raman instrument where the biosignatures of relict or extant life could remain in the geological record.

(C) 2006 Elsevier B.V. All rights reserved.
\end{abstract}

Keywords: Raman spectroscopy; Mars analogue; Rio Tinto; Acidotrophic; Astrobiology; Spectral biomarkers

\section{Introduction}

Knowledge of the terrestrial conditions under which organisms can colonise environments which represent extremes of temperature, radiation insulation, pressure, desiccation, salinity and $\mathrm{pH}$ leads to a better understanding of their survival strategies [1,2]. Survival of extremophile colonies in geological matrices and substrates depends fundamentally upon mecha-

\footnotetext{
* Corresponding author. Tel.: +44 1274 233787; fax: +44 1274235600.

E-mail addresses: h.g.m.edwards@bradford.ac.uk

(H.G.M. Edwards), peter.vandenabeele @UGent.be (P. Vandenabeele), seju@ubu.es, susanajorgevillar@hotmail.com (S.E. Jorge-Villar), e.carter@chem.usyd.edu.au (E.A. Carter), rull@fmc.uva.es (F.R. Perez), m.hargreaves@bradford.ac.uk (M.D. Hargreaves).

1 Tel.: +32926466 23; fax: +3292646699.

2 Tel.: +34947 258772; fax: +34947258892.

3 Tel.: +61 29365 1279; fax: +61 293513329 .

${ }^{4}$ Tel.: +34983423195.
}

nisms of avoidance of harmful conditions, for example like UV radiation and the production of protective biochemicals through which the tolerance and adaptation to the hostile environmental conditions can be accomplished [3]. In addition current interest in the area has been generated through the recent identification of similar geological niches or structures on Mars [4-7].

In 2004, the NASA Mars Exploration Rover "Opportunity" identified for the first time using Mossbauer spectroscopy the presence of jarosite, a potassium iron sulfate mineral, at a site known as El Capitan, a rock outcrop in the Meridiani Planum region of Mars [8-11]. The world-type locality [12] for jarosite is the Jaroso Ravine near Huelva, Spain, which along with the Jaroso Hydrothermal System has now been proposed as a terrestrial Mars analogue site of possible astrobiological relevance [13-15]. A particular characteristic of the Jaroso Ravine area is the highly coloured, deep red Rio Tinto ('Red River'), which supports microbial life under extremely acidic conditions ( $\mathrm{pH} \sim 2$ or lower) along with sulfur-rich mineral deposits such 

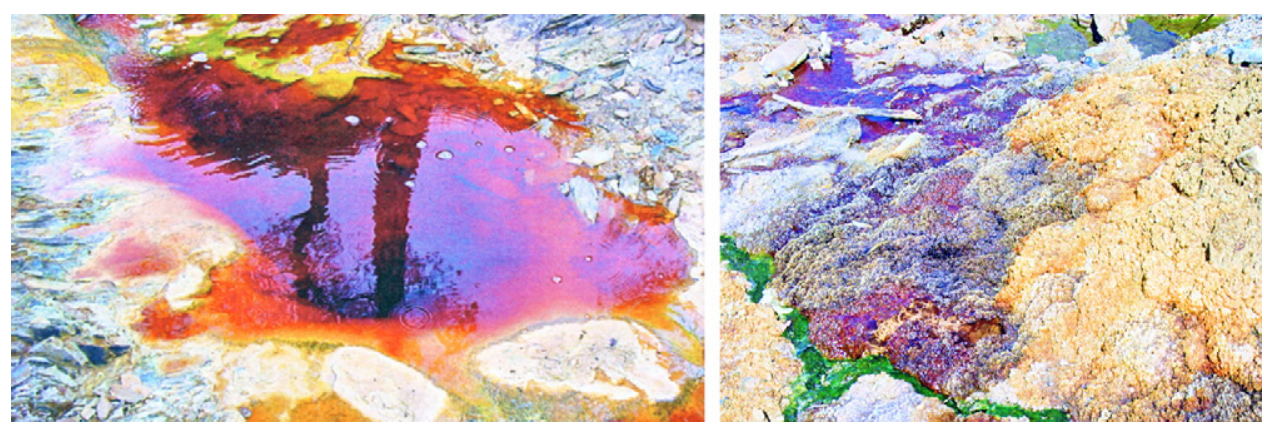

Fig. 1. Rio Tinto pool and mineral deposits.

as copiapite, jarosite, schwertmannite, halotrichite and gypsum (Fig. 1).

During a field trip to the Rio Tinto region undertaken as part of the GeoRaman VI meeting in Almuñecar, Spain, several specimens of the efflorescent mineral deposits at the edge of the Rio Tinto River were collected along with surface colonising extremophiles. These have been subjected to Raman spectroscopic analysis with the view of determining the presence of key spectral biological signatures that may have arisen from the protective strategies adopted by any existing extremophiles. Several previous studies of extremophilic colonisation have demonstrated the viability of Raman spectroscopy for the in situ determination of extinct or extant biological material in the geological matrix, without involving the separation of the biological colonies from their inorganic mineral host matrices. This approach provides novel information at the molecular level about the important organic/inorganic interactions [1,2,16-18].

\section{Experimental}

\subsection{The site}

The Rio Tinto Mars Analogue site comprises the Jaroso Hydrothermal System [13], which is rich in iron $(\sim 25,000 \mathrm{ppm})$ and sulfur $(\sim 110,000 \mathrm{ppm})$, with a deep blood-red river whose pigmentation (Fig. 1) is attributed to the microbial production of ferrihydrite, an iron oxyhydroxide. The acidity of the river varies seasonally from about $\mathrm{pH} 1.5$ to 3.0 and green algal mats are observed at the water's edge and in isolated pools in the Jaroso Ravine. There is extensive mineral deposition and efflorescence at the water's edge, comprising significant quantities of sulfates such as jarosite, halotrichite, copiapite and gypsum (Fig. 2). Although specimens of these deposits have previously been analysed using Raman spectroscopy $[15,19,20]$, no evidence of biological presence was found; the present work specifically addresses this issue and will characterise any biomarkers which could possibly have relevance to similar geological deposits recently found on Mars and identified by the Mossbauer spectrometer on board the MER "Opportunity". Contrary to this view, current opinion tends to localize the biology in the aqueous phase only [21], despite this, several specimens of epilithlic extremophiles have been collected near the waters edge.

Specimens of the efflorescent mineral deposits and epiliths were collected at the water's edge from several sites along the Jaroso Ravine; the identification, or otherwise, of any key biomarker features in the Raman spectra will be a critical phase of our work and will afford a possible lead into the strategy adopted by these acidophiles for survival in the Rio Tinto scenario.

\subsection{Specimens}

Several specimens of efflorescent minerals from the "Escombrera Grande" (1EG and 13EG) and "Puente" (P7) sites were taken along with a specimen of jarosite (JARO1105). Other specimens of epilithic lichen growth on dead wood at the edge of pools of the Rio Tinto were also taken.

\subsection{Raman spectroscopy}

Raman spectroscopy was performed using a Renishaw InVia Reflex System spectrometer (Renishaw plc, Wotton-UnderEdge, UK). The instrument is equipped with several lasers with numerous laser wavelengths emitting at $785,633,514.5$ and $488 \mathrm{~nm}$ with a maximum output power of $50 \mathrm{~mW}$. Laser power at the sample could be minimised to ca. $5 \mu \mathrm{W}$, by using a set of neutral density filters. In order to account for sample inhomogeneity, a minimum of three spectra, but up to ca. 100 Raman spectra were recorded using a $50 \times$ objective lens, which provides a spot size of ca. $2 \mu \mathrm{m}$. Spectra were recorded at a spectral resolution of $2 \mathrm{~cm}^{-1}$ between 50 and $1800 \mathrm{~cm}^{-1}(20-90$ accumulations of

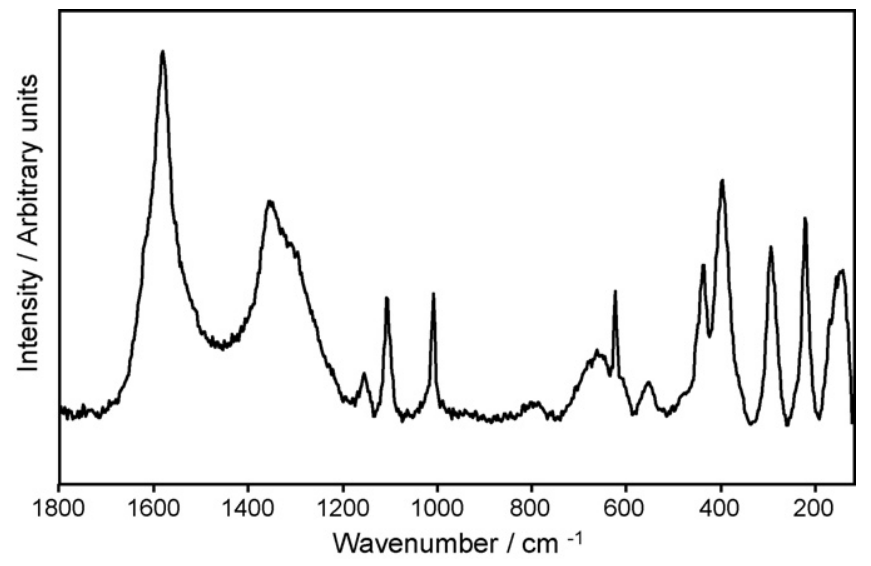

Fig. 2. Raman spectrum of mineral deposits in Rio Tinto: $785 \mathrm{~nm}$ excitation, wavenumber range $100-1800 \mathrm{~cm}^{-1}$. 
$10 \mathrm{~s}$ each) and in some cases between 400 and $1800 \mathrm{~cm}^{-1}$ (min. five accumulations of $30 \mathrm{~s}$ each).

\section{Results and discussion}

\subsection{Mineralogy}

Jarosite is the most commonly found mineral in the geological matrices of the specimens and it can be clearly identified from characteristic Raman bands (1152, 1104, 1007, 624, 572, $451,431,354,299,223 \mathrm{~cm}^{-1}$ ) which have been reported hitherto $[15,19]$ and are listed in Table 1. Raman bands attributed to goethite are also observed, along with several iron oxides (Fig. 3a). A number of bands have been tentatively assigned to a sulfate containing mineral, however this mineral has not yet been identified (Fig. 3b). An iron sulfate with four water molecules is identified by the Raman signatures at 994, 479, 455,303 and $269 \mathrm{~cm}^{-1}$; the band at 986 is characteristic to barytes. The Raman bands observed at 1135, 1008, 669, 613, 492 and $413 \mathrm{~cm}^{-1}$ in Fig. $3 \mathrm{c}$ are characteristic of gypsum. In other spectra (not shown here), the quartz, wursite and haematite

Table 1

Minerals and organic compounds

\begin{tabular}{ll}
\hline & Raman bands $\left(\mathrm{cm}^{-1}\right)$ \\
\hline Mineral & \\
Jarosite & $1152,1104,1007,624,572,451,431$, \\
& $354,299,223$ \\
Goethite & $550,475,386,299,241$ \\
Unidentified sulfate & $1019,613,597,474,456,303,269$ \\
Iron sulfate 4 water molecules & $994,479,455,303,269$ \\
Gypsum & $1135,1008,669,613,492,413$ \\
Microbiology & \\
Micosporine-like amino acid & $1493,1414,1340,1293,1215,1181$, \\
compound & $1150,920,845,485$ \\
Lutein & $3034,2675,2526,2308,2159,1526$, \\
& 1156,1002 \\
Chlorophyll & $3034,2675,2526,2308,2159,1324$ \\
Scytonemin & $1713,1632,1603,1592,1552,1547$, \\
& $1520,1446,1386,1324,1282,1247$, \\
& $1168,1096,1078,1024,984,910,888$, \\
& $839,779,753,677,660,576,540,497$, \\
& 307,271
\end{tabular}

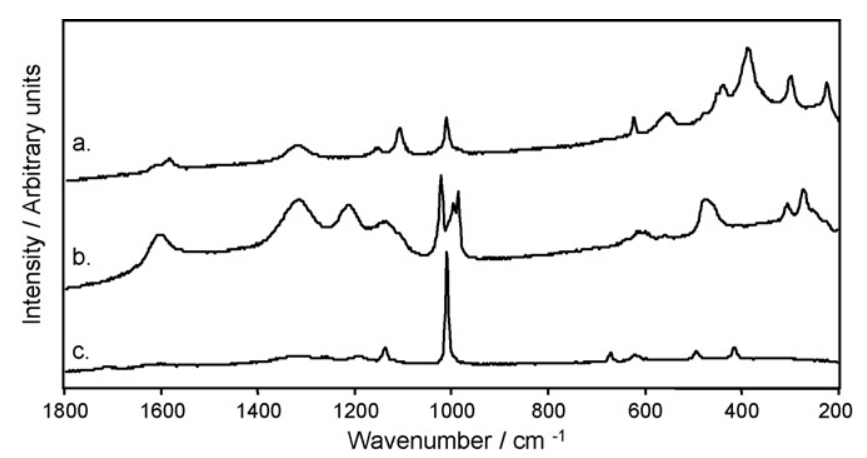

Fig. 3. Raman spectra of Rio Tinto minerals: (a) a mixture of iron oxides, including goethite, (b) an iron sulfate containing mineral, (c) gypsum. The $\mathrm{sp}^{2}$ and $\mathrm{sp}^{3}$ hybridised carbon can also be identified in these spectra.

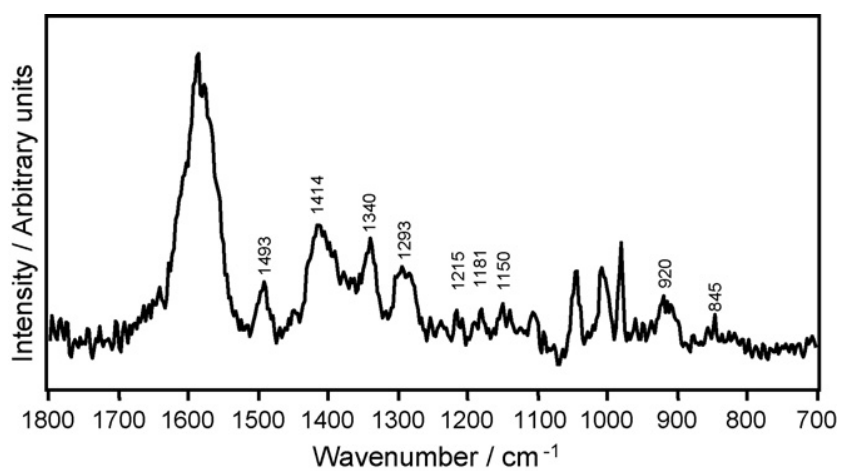

Fig. 4. Raman spectra of efflorescence samples.

signatures have been identified; this is indicative of the richness and heterogeneity of the specimens under study.

In the specimen of jarosite (JARO1105), Raman bands at $1493,1414,1340,1293,1215,1181,1150,920,845$ and $485 \mathrm{~cm}^{-1}$ have been assigned to a mycosporine-like amino acid (MAA) compound (Fig. 4). Several spectra from other sampling points in this specimen in the wavenumber region characteristic for organic compounds $\left(1000-1800 \mathrm{~cm}^{-1}\right)$; these have not been assigned to particular compounds and we can infer that these compounds could exhibit degradation. The spectrum in Fig. 5a exhibits bands at 1693 (quinine carbonyl), 1597 (carbon), 1450, 1315 (carbon), 1249 and $1135 \mathrm{~cm}^{-1}$. Raman bands at 1587 and $1414 \mathrm{~cm}^{-1}$ are observed in addition in the spectrum shown in Fig. 5b; in Fig. 5c the signatures at 1605, 1493, 1414 and $1340 \mathrm{~cm}^{-1}$ have been assigned to a mycosporine-like amino acid. Fig. $5 \mathrm{~d}$ exhibits broad bands at 1573 and at $1360 \mathrm{~cm}^{-1}$ and a weak shoulder at $1300 \mathrm{~cm}^{-1}$. It is clear that these bands are indicative of $\mathrm{CH}, \mathrm{CC}$ and $\mathrm{CO}$ modes with ring structures in the spectrum, probably sharing some degradation.

Two samples of the six specimens sampled at the water's edge of the Rio Tinto ravine, contained epiliths with major Raman bands observed at 1526,1156 and $1002 \mathrm{~cm}^{-1}$ indicative of a carotenoid, probably lutein (Fig. 6) [17,18]. In addition, the Raman spectra of one of these samples has a feature at $1324 \mathrm{~cm}^{-1}$ which is assignable to chlorophyll, whereas both

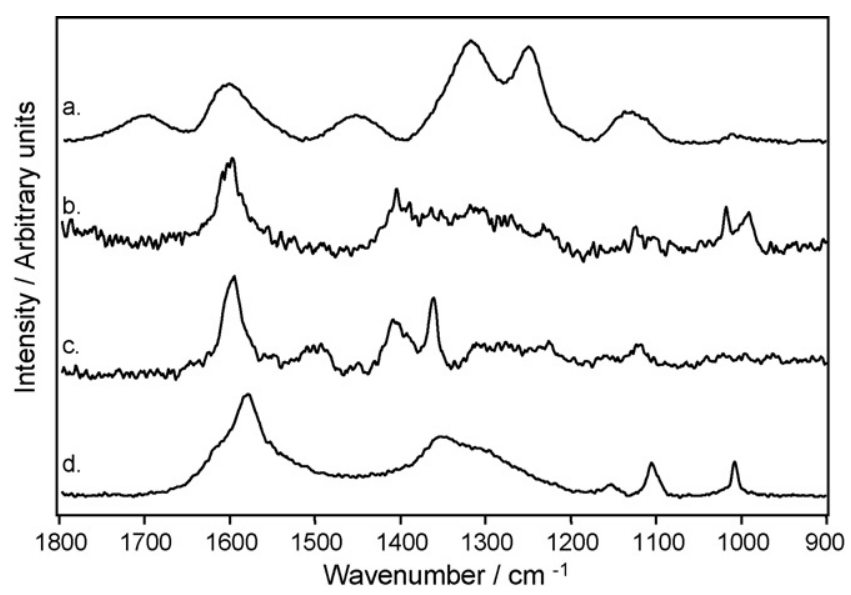

Fig. 5. Raman spectra of mycosporine-like amino acid in the Rio Tinto mineral specimen. 


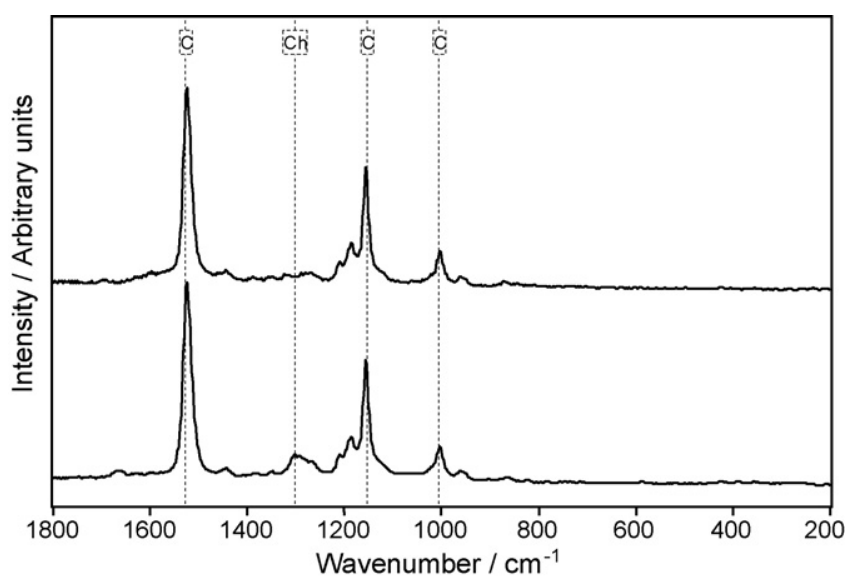

Fig. 6. Raman spectra recorded from two samples at the edge of the Rio Tinto River. C: Carotenoid, Ch: chlorophyll, $488 \mathrm{~nm}$ excitation, $10 \mathrm{~s}$ exposure, wavenumber range $1800-200 \mathrm{~cm}^{-1}$.

have a weaker band at $3043 \mathrm{~cm}^{-1}$ (not shown), assignable to unsaturated $\mathrm{C}=\mathrm{CH}$ bonds, probably in the carotenoid skeletal backbone. No features due to a mineral phase can be noted in these specimens.

The spectra of the remaining four samples of the Rio Tinto area show some distinctive Raman bands and also some that have similarities with the two discussed previously. The stack plotted spectra in Fig. 7 show evidence of a carotenoid from Raman bands at 1526, 1156 and $1002 \mathrm{~cm}^{-1}$, probably lutein, but spectrum d in Fig. 7 shows evidence of scytonemin with features at $(1712,1629,1599,1485,1435,1382,1324,1249$, $1171,1095,1022,983,908,779,765,753,677,659,637,628$, $576,494,462,437,306)$, together with a different carotenoid, probably asthaxanthine with bands at 1508,1152 and $1004 \mathrm{~cm}^{-1}$ [18]. This particular spectrum is interesting for several reasons, but specifically since scytonemin is exclusively produced by cyanobacteria as a UV-radiation protectant biomolecule. The need for production of a different carotenoid therefore seems to be part of the extremophilic strategy being adopted by the cyanobacteria.

Several regions in the specimens showed black particles, which yielded spectra of the mineral phase and carbon only;

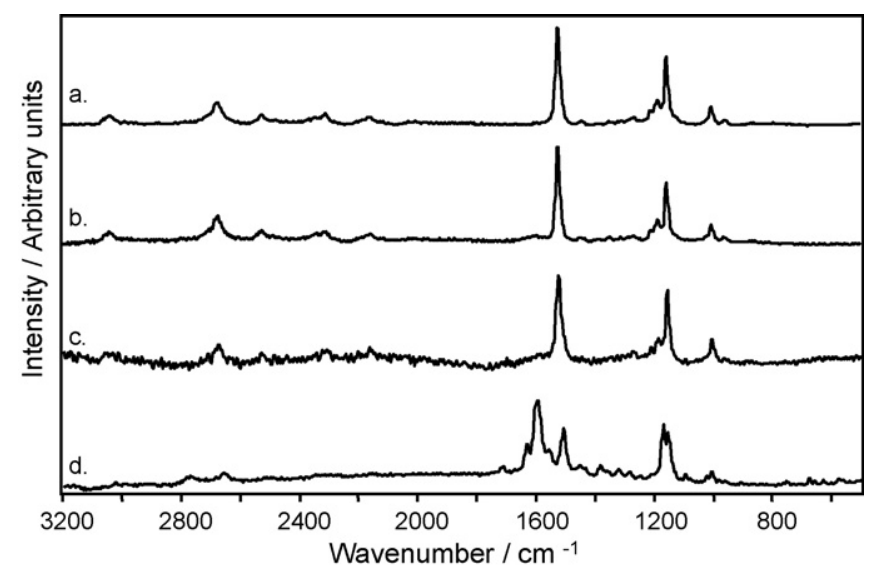

Fig. 7. Raman spectra of Rio Tinto eplithilic and endolithic specimens, $488 \mathrm{~nm}$ excitation, $10 \mathrm{~s}$ exposure, wavenumber range $3200-500 \mathrm{~cm}^{-1}$. it can be inferred therefore that the strategies adopted by extremophilic colonies at these sites was not effective enough to ensure their survival and their organic components have been degraded to carbon.

\section{Conclusion}

In this work, several samples from the Rio Tinto region were examined by Raman spectroscopy. The capability of Raman spectroscopy for the detection of minerals and organic compounds in a mixture has led to adoption by the European Space Agency (ESA) as part of a life-detection instrumental suite to be sent to Mars for the Exomars project.

Using this technique we have identified several types of minerals, such as jarosite, goethite, gypsum, iron oxides and sulfates, some of these have also been identified on the Martian planetary surface [22-25].

For the first time, biological signatures have been detected using Raman spectroscopy in Rio Tinto. The identification by the NASA rover "Opportunity" of jarosite in a crater on the Martian surface has made of Rio Tinto an important terrestrial Mars analogue site on Earth [15]. The presence of microorganisms related with this acid environment in the Rio Tinto site therefore confers the observation of jarosite and related minerals by the Martian Meridiani Planum into an area of high interest for the search for life signatures on Mars. The biomolecules detected in the specimens analysed in this work include two carotenoids, lutein, asthaxanthine, chlorophyll, scytonemin, (a cyanobacterial UV-protection molecule) as well as a mycosporine-like amino acid and other unidentified biosignatures which perhaps relate to partially degraded material.

\section{Acknowledgements}

Howell Edwards and Michael Hargreaves acknowledge PPARC and EPSRC for financial support. Peter Vandenabeele acknowledges the Research Foundation-Flanders (F.W.O.Vlaanderen) for its financial support and for his postdoctoral Grant.

\section{References}

[1] D.D. Wynn-Williams, H.G.M. Edwards, Icarus 144 (2000) 486.

[2] D.D. Wynn-Williams, H.G.M. Edwards, Planet. Space Sci. 48 (2000) 1065

[3] C.S. Cockell, J.R. Knowland, Biol. Rev. 74 (1999) 311.

[4] B.C. Clark, J. Geophys. Res. Planets 103 (1998) 28545

[5] P.T. Doran, R.A. Wharton, D.J. des Marais, C.P. McKay, J. Geophys, Res. Planets 103 (1998) 28481.

[6] J. Farmer, J. Geophys, Res. Planets 103 (1998) 28457.

[7] S.J. Mojzsis, G. Arrhenius, J. Geophys, Res. Planets 103 (1998) 28495.

[8] S.W. Squyres, J.P. Grotzinger, R.E. Arvidson, J.F. Bel III, W. Calvin, P.R. Christensen, B.C. Clark, J.A. Crisp, W.H. Farrand, K.E. Herkenhoff, J.R. Johnson, G. Klingelhofer, A.H. Knoll, S.M. McLennan, H.Y. McSween, R.V. Morris, J.W. Rice, R. Rieder, L.A. Soderblom, Science 306 (2004) 1709.

[9] M.E.E. Madden, R.J. Bodiar, J.D. Rinstidt, Nature 431 (2004) 821.

[10] G. Klingelhofer, R.V. Morris, B. Bernhardt, C. Schroder, D.S. Radionov, P.A. de Souza, A. Yen, R. Gellert, E.N. Evlanov, B. Zubkov, J. Foh, U. Bornes, E. Kankeleit, P. Gutlich, D.W. Ming, F. Renz, T. Wdowiak, S.W. Squyres, R.E. Arvidson, Science 306 (2004) 1740. 
[11] P.R. Christensen, M.B. Wyatt, T.D. Glotch, A.D. Rogers, S. Anwar, R.E. Arvidson, J.L. Bandfield, D.L. Blaney, C. Budney, W.M. Calvin, A. Fallacarro, R.L. Fergason, N. Gorelick, T.G. Graff, V.E. Hamilton, A.G. Hayes, J.R. Johnson, A.T. Knudson, H.Y. McSween, G.L. Mehall, L.K. Mehall, J.E. Moersch, R.V. Morris, M.D. Smith, S.W. Squyres, S.W. Ruff, M.J. Wolff, Science 306 (2004) 1733.

[12] J. Martinez Frias, AMBIO J. Hum. Environ. 28 (1999) 204.

[13] J. Martinez Frias, R. Lunar, J.A. Rodriguez Losada, A. Delgado, Earth Planet. Space Sci. 56 (2004) 5.

[14] R. Grymes, R. Briggs, EGU Geophys. Res. Abstr. 7 (2005), Abstr. No. 09899.

[15] F. Rull, J. Martinez Frias, J. Medina, EGU Geophys. Res. Abstr. 7 (2005), Abstr. No. 09114.

[16] H.G.M. Edwards, E.M. Newton, in: J.A. Hiscox (Ed.), The Search for Life on Mars, British Interplanetary Soc., London, 1999, p. 83.
[17] D.D. Wynn-Williams, H.G.M. Edwards, in: G. Horneck, C. BaumstarckKhan (Eds.), Astrobiology: The Quest for the Origins of Life, Springer Verlag, Berlin, 2000 (Chapter 16).

[18] S.E. Jorge-Villar, H.G.M. Edwards, Anal. Bioanal. Chem. (2006).

[19] R.L. Frost, M.L. Weier, J.T. Klopprogge, F. Rull, J. Martinez Frias, Spectrochim. Acta 62A (2005) 166.

[20] F. Rull, J. Martinez Frias, J. Medina, A. Sanz, E. Gonzalez-Pastor, in: S. Sharma (Ed.), GeoRaman V Abstracts, Hawaii, 59, 2004.

[21] R. Amils, personal communication, 2006.

[22] G. Klingelhöfer, R.V. Morris, A.S. Yen, D.W. Ming, C. Schröder, D. Rodinov, Geochim. Cosmochim. Acta 70 (2006) 23.

[23] G. Klingelhöfer, B. Bailey Jr., R.V. Morris, E. Kankeleit, P. Held, E. Evlanov, O. Priloutskii, Planet. Space Sci. 44 (1996) 1277.

[24] C. Schröder, B. Bailey, G. Klingelhöfer, H. Staudigel, Planet. Space Sci.

[25] V. Chevrier, P.E. Mathé, Planet. Space Sci. 